\title{
BRUCELLOSIS IN RUMINANT ANIMALS AND THEIR CLOSE CONTACT HUMANS IN WESTERN REGION OF SAUDI ARABIA IN 2012
}

\author{
ABD EL-RAHIM I.H.A. ${ }^{(* * * *)}$ and ASGHAR A.H** \\ * Professor of Infectious Diseases and Epizootiology, Department of Environmental \& Health Research, The Custodian of \\ the Two Holly Mosques Institute of Hajj \& Umrah Research, Umm Al-Qura University, P.O. 6287, 21955 Makkah, \\ Saudi Arabia \\ ** Associate Professor of Medical Microbiology, Department of Environmental \& Health Research, The Custodian of the \\ Two Holly Mosques Institute of Hajj \& Umrah Research, Umm Al-Qura University, P.O. 6287, 21955 Makkah, Saudi \\ Arabia. \\ *** Infectious Diseases, Department of. Animal Medicine, Faculty of Veterinary Medicine, Assiut University, 71526 Assiut, \\ Egypt. \\ Email: vetrahim@yahoo.com
}

\begin{tabular}{|c|c|}
\hline & ABSTRACT \\
\hline Received at: $28 / 10 / 2013$ & $\begin{array}{l}\text { The current study recorded an overall incidence of } 9.3 \% \text { (76/818) of } \\
\text { brucellosis in small ruminants in western region (Makkah and Al-Madinah), } \\
\text { Saudi Arabia in } 2012 \text {. The incidence was } 14.2 \% \text { (70/492) and } 1.8 \%(6 / 326) \text { in } \\
\text { Makkah and Al-Madinah, respectively. Regarding the animal species, the } \\
\text { incidence was } 15.6 \% \text { (59/377) and } 3.9 \% \text { (17/441) in sheep and goats, } \\
\text { respectively. All animal sera which were positive for Brucella antibodies using } \\
\text { Rose Bengal Test (RBT) were also positive in indirect enzyme linked immune } \\
\text { sorbent assay (ELISA). In Makkah, the incidence of brucellosis in the human } \\
\text { beings was 2.7\% (3/113) using agglutination test. The seropositive human } \\
\text { cases were infected most probably as a result of their close contact with living } \\
\text { or slaughtered infected sheep and goats during their daily work. This study } \\
\text { concluded that Brucella infection is posing threat to both animal and human } \\
\text { health in Saudi Arabia. The existing vaccination program should be strictly } \\
\text { implemented with numbering and recording of the vaccinated animals. } \\
\text { Prevention of human brucellosis in Saudi Arabia will ultimately depend on the } \\
\text { eradication of the disease in ruminant animals. Further studies for investigating } \\
\text { the incidence of brucellosis in human beings and ruminant animals all over the } \\
\text { country are recommended. }\end{array}$ \\
\hline
\end{tabular}

Key words: Brucellosis - ELISA - Human beings - Rose Bengal Test (RBT) - Saudi Arabia - Slide agglutination test - Small ruminants.

\section{INTRODUCTION}

Brucellosis is a highly contagious zoonosis caused by Gram negative coccobacilli of the genus Brucella. It is a sub-acute or chronic disease which may affect many species of animals (Corbel, 1997; Seimenis et al., 2006). It can cause considerable economic losses in the livestock industry because of abortions, decreased milk production, sterility, and veterinary care and treatment costs (Corbel, 1997; Corbel and MacMillan, 1999). There are four important species pathogenic to humans: Brucella melitensis, found primarily in goats, sheep and camels; Brucella abortus in cattle; Brucella suis in pigs; and Brucella canis in dogs. The Brucella species differ in degree of virulence and invasiveness. Brucella melitensis is the most invasive and produces the most severe disease. Brucella abortus is the least invasive and causes the mildest illness (Al-Eissa, 1999).

The disease occurs in many parts of the world. There are only a few countries in the world that are officially free of the disease, although cases still occur in people returning from endemic countries (Corbel and Beeching, 2004). In Saudi Arabia, human infection with Brucella melitensis is commonly encountered (80\%-100\%), and infection with Brucella abortus is less frequent (Kambal et al., 1983; Al-Eissa et al., 1990), while infection with other species has not been reported (Al-Eissa, 1999).

Brucellosis is common in the central region of Saudi Arabia (Kiel and Khan, 1987). The incidence of brucellosis in goats in Makkah in 1977 was found to be $0.8 \%$, in sheep $0.5 \%$, in camels $2.8 \%$ and in cows $3.6 \%$ (Radwan et al., 1983). While the incidence in 
the Asir region in 1987 was $18.2 \%$ in goats, $12.3 \%$ in sheep, $22.6 \%$ in camels and $15.5 \%$ in cows (Bilal et al., 1991). Memish (2001) stated that despite brucellosis control in many developed countries the disease remains endemic in Saudi Arabia where the national seroprevalence of the disease is $15 \%$.

Brucellosis is endemic disease in the Kingdom of Saudi Arabia (KSA). Since 1990 vaccination of small ruminants using the live attenuated Brucella melitensis Rev.1 vaccine, without numbering and recording of the vaccinated animals, was applied. Seropositive cases among non-vaccinated small ruminants as well as human beings are still reported.

The current study aims study aims to estimate the incidence of brucellosis in small ruminants and their close contact people in western region (Makkah and Al-Madinah), Saudi Arabia. Furthermore, the study intends to correlate the history of the disease and the serological status of infected human beings, and to discuss the disease control program in Saudi Arabia.

\section{MATERIALS and METHODS}

\section{Sampling}

\section{Serum samples from small ruminants}

From January to April 2012, a total of 818 blood samples from small ruminants were collected from Makkah and Al-Madinah, Saudi Arabia. On the basis of historical data, the sampled animals were not vaccinated against brucellosis. Approximately 20$30 \%$ of adult female sheep and goats in the investigated farms were sampled. In Makkah, a total of 492 blood samples were collected from four different stockyards (188 samples from Al-ka'kia, 41 samples from Al-Juarana, 146 samples from Almoasim and 117 samples from Al-shara'ia). In AlMadinah, 326 blood samples were collected from three different stockyards (103 samples from Aloyon, 49 samples from Al-azizya, and 174 samples from Al-dua'itha).

\section{Serum samples from human beings}

One hundred and thirteen blood samples from human beings were obtained from Makkah. They include 3 veterinarians, 33 butchers and 43 farm workers at AlKa'kia abattoir; and 34 farm workers from Alshara'ia. According to the nature of their work, the investigated people are always in close contact with either living animals, carcasses or both. Two of the human beings cases were with a previous history of Malta fever, while the rest were without history of the disease. Obtaining of blood samples from human beings in Al-Madinah was not available.

Both human and animal blood samples were labeled and delivered to the laboratory in ice box. The coagulated blood samples were centrifuged at 1000 rpm for about 5-10 minutes. The above serum layer was aspirated into $2 \mathrm{ml}$ eppendorf tubes then labeled and kept at $-20^{\circ} \mathrm{C}$ until serological testing.

\section{Serodiagnosis of animal brucellosis}

Rose Bengal antigen (Institut Pourquier, IDEXX Laboratories, France) was used for serodiagnosis of animal brucellosis. For confirmation of RBT seropositive cases, all ovine and caprine positive sera were retested using indirect ELISA (Brucellosis antibody test kit, IDEXX, France). All serological assays were carried out as recommended by the manufacturers and according to the provisions of the OIE manual for terrestrial animals (World Organisation for Animal Health, 2009).

\section{Serodiagnosis of human brucellosis}

Rapid slide agglutination test was used for screening of the human serum samples. Stained antigen suspensions (Febrile Antigen, Crescent Diagnostics, Ireland) were used for the identification of specific Brucellae (FB850/851-9 Brucella abortus and FB850/851-10 Brucella melitensis) antibodies in human sera. The positive sera were titrated using tube agglutination test (Young, 1991). The screening test and titration were carried out according to the method of the manufacture.

\section{RESULTS}

\section{Serological incidence of brucellosis in small ruminants}

\section{Rose Bengal Test (RBT)}

Totally, 76 out of $818(9.3 \%)$ tested serum samples were positive using RBT. Among sera collected from Makkah, $53(19.8 \%)$ out of 267 sheep sera were positive, while 17 (7.5\%) out of 225 tested goat sera were positive. Regarding to the serum samples that were obtained from Al-Madinah, 6 (5.5\%) out of 110 sheep sera were positive, while all 216 obtained goat sera were negative (Table 1). According to the animal species, $59(15.6 \%)$ out of 377 investigated sheep were seropositive, while 17 (3.9\%) out of 441 tested goats were seropositive (Table 2).

\section{Indirect ELISA}

All ovine and caprine positive tested sera $(n=76)$ which were positive for Brucella antibodies using RBT were also positive in indirect ELISA.

\section{Serological incidence of brucellosis in contact people}

\section{Rapid slide agglutination test}

In human beings, three individuals $(2.7 \%)$ out of 113 , including a butcher (at Al-ka'kia abattoir) and two farm workers (from Al-Shar'ia), were positive for 
Brucella antibodies using rapid slide agglutination test (Table 3).

\section{Tube agglutination test}

By using the tube agglutination test, the titer was $1 / 160$ of two cases, one case under treatment and the other one was treated for about one year, whereas the titer was $1 / 320$ in the third case, which was without either history or clinical signs of the disease (Table $3)$.

Table 1: The incidence seropositive animals in both Makkah and Al-Madinah.

\begin{tabular}{|c|c|c|c|c|c|}
\hline \multirow[t]{2}{*}{ Locations } & \multirow[t]{2}{*}{ Animal species } & \multirow[t]{2}{*}{ Breeds } & \multirow[t]{2}{*}{ Total tested } & \multicolumn{2}{|c|}{ Seropositive animals } \\
\hline & & & & Number & $\%$ \\
\hline \multirow{3}{*}{ Makkah } & Sheep & Harri & 267 & 53 & 19.8 \\
\hline & Goats & Harri & 225 & 17 & 7.5 \\
\hline & Subtotal & & 492 & 70 & 14.2 \\
\hline \multirow{3}{*}{ Al-Madinah } & Sheep & Najjdi & 110 & 6 & 5.5 \\
\hline & Goats & Harri & 216 & 0 & 0.0 \\
\hline & \multicolumn{2}{|c|}{ Subtotal } & 326 & 6 & 1.8 \\
\hline Total & & & 818 & 76 & 9.3 \\
\hline
\end{tabular}

Table 2: The overall incidence of brucellosis in regarding to the animal species.

\begin{tabular}{cccc}
\hline Animal species & Total tested & \multicolumn{2}{c}{ Seropositive animals } \\
\cline { 3 - 4 } & & Number & $\%$ \\
\hline Sheep & 377 & 59 & 15.6 \\
\hline Goats & 441 & 17 & 3.9 \\
\hline Total & 818 & 76 & 9.3 \\
\hline
\end{tabular}

Table 3: The incidence of human brucellosis in Makkah.

\begin{tabular}{cccccc}
\hline \multirow{2}{*}{ Location } & Total tested human sera & \multicolumn{2}{c}{ Seropositive animals } & \multicolumn{2}{c}{ Titer } \\
\cline { 3 - 6 } & & Number & $\%$ & $1 / 160$ & $1 / 320$ \\
\hline \multirow{2}{*}{ Makkah } & 113 & 3 & 2.7 & 2 & 1 \\
\hline
\end{tabular}

\section{DISCUSSION}

In this study, a sero-epidemiological survey on brucellosis in small ruminants and their close contact people was carried out in Makkah and Al-Madinah, Saudi Arabia during 2012. The overall incidence of Brucella infection in small ruminants was $9.3 \%$. In Makkah and Al-Madinah, the incidence of animal brucellosis was 14.25 and $1.8 \%$ respectively. In countries of the Near East region, brucellosis was reported in almost all domestic animals, particularly cattle, sheep and goats (Refai, 2002). The present study was concerned with the incidence of brucellosis in sheep and goats, because they are considered the main source of infection for human beings in Saudi Arabia (Memish, 2001).

In regarding to the animal species, the incidence in the current study was $15.6 \%$ and $3.9 \%$ in sheep and goats respectively. In Saudi Arabia, previously in
1977, the incidence of brucellosis in goats in Makkah (western region) was found to be $0.8 \%$ and in sheep $0.5 \%$ (Radwan et al., 1983). Ten years later in 1987, higher incidence was reported in the Asir region (southern region), where it was $18.2 \%$ in goats and $12.3 \%$ in sheep (Bilal et al., 1991). In other countries, the prevalence of brucellosis in sheep and goats respectively was $2.18 \%$ and $12 \%$ in Algeria (Refai, 2000); $1.4 \%$ and $3.8 \%$ in Eritrea (Omer et al. 2000); $1 \%$ and $4 \%$ in Sudan (El-Ansary et al., 2001); $3.42 \%$ and $5.53 \%$ in India (Sharma et al., 1979); $2 \%$ and 3.4\% in United Arab Emirates (Afzal and Sakkir, 1994); and $1.6 \%$ and $6.4 \%$ in Oman (WHO,1998).

Saudi Arabia is one of the countries with the highest incidence of human brucellosis (Refai, 2002). The recorded incidence of brucellosis among the tested human sera in the present study was $2.7 \%$, where 3 (one butcher and two farm workers) out of 113 collected sera were positive for Brucella antibodies. 
National statistics in Saudi Arabia indicated that the disease incidence in humans is close to 40 cases per 100,000 (Memish, 2001). Previously, incidence rates of $1 \%-22 \%$ have been reported among human beings in Saudi Arabia and other countries (Kato et al., 2007). In 3 years, over 500 positive patients who had a titer of 1:160 or more were identified in the central region of Saudi Arabia (Kiel and Khan, 1987).

Human brucellosis may be present with a broad spectrum of clinical manifestations (Solera et al., 1997). In the current study, two cases (farm workers) out of the three seropositive human cases had a previous history of Brucella infection, whereas the third case (butcher at Al-ka'kia abattoir) was without either history or clinical signs of the disease. This case may be suffered from subclinical infection. This agreed with Alton and Forsyth (1996) and Magwedere et al. (2011) how stated that the presentation of brucellosis in human beings is characteristically variable. The onset may be insidious or abrupt. Subclinical infection is common.

Two cases out of the three seropositive human cases in this study had a titer of $1 / 160$. According to the history of the disease, one case was under treatment and the other one was treated for about one year. In the third subclinically infected case, the titer was 1/320. Young (1991) found that most patients with active brucellosis had agglutinin titers of $\geq 160$. During a serological survey on human brucellosis in the central region of Saudi Arabia, the lower titers were less useful as indicators of active disease in the investigated population, in which many people appear to have persistent low antibody levels (Kiel and Khan, 1987).

Brucellosis acquired from handling of infected animals or consuming contaminated milk or milk products. Exposure is frequently occupational (Alton. and Forsyth, 1996). The main source of infection for the three seropositive human cases that reported in the current study was mostly the frequent exposure to infected materials during their work. According to the microorganism species, they were most probably infected with Brucella Melitensis as a result of daily direct and indirect contact with the living or slaughtered infected sheep and goats. Also, it was stated that Brucella melitensis remains the principle cause of human brucellosis in Saudi Arabia, causing $88-93 \%$ of the cases (Memish, 2001).

The major clue to the diagnosis of brucellosis is serologic testing (Kiel and Khan, 1987). Diagnosis of brucellosis in the present study was depending on serological testing. Animal brucellosis was diagnosed using RBT and confirmed with indirect
ELISA, while agglutination tests were used for detection and titration of the Brucella antibodies in the tested human serum samples. All 76 animal sera which were positive for Brucella antibodies using RBT were also positive in indirect ELISA.

Human brucellosis is endemic in Northern Saudi Arabia as in other parts of the kingdom (Fallatah et al., 2005). In human beings, the main modes of Brucella transmission are considered to be dietary, the consumption of contaminated dairy products, occupational exposure, and exposure to infected livestock (Pappas et al., 2006; Gul and Khan, 2007). The present study suggested that the use of protective measurements when in contact with the livestock and pasteurization of sheep and goats milk before consumption, particularly in rural areas, will reduce the risk of human infection in Saudi Arabia.

In Saudi Arabia the disease is introduced through uncontrolled importation of animals that are poorly screened for the disease. In addition, the KSA imports annually a few million heads of sheep and goats for sacrifice during Hajj from Africa (Memish, 2001). So that avoiding importation of small ruminants from countries where brucellosis is enzootic as well as strict application of the quarantine measurements may help disease control in Saudi Arabia.

Prevention of brucellosis in humans still depends on the eradication or control of the disease in animal hosts (Corbel, 1997). There is an urgent need for a national program for controlling brucellosis in the KSA. The components of this program will include recruitment and training of qualified veterinarians, development of an adequate number of animal quarantine centers and implementing legislation to control marketing and movement of animals (Bilal et al., 1991). The current study suggested that the eradication of human brucellosis in Saudi Arabia will ultimately depend on the eradication of animal brucellosis. For eradication of the disease in ruminant animals, test and slaughter program may be advised.

The current study concluded that brucellosis is still causing problem for both animal and human health in some parts of the Saudi Arabia, where seropositive cases are still reported in small ruminant animals and human beings. Improper applications of the existing vaccination program and continuous importation of small ruminants from brucellosisenzootic African countries are probably the two main causes of the reoccurrence of infection and endemicity of the disease in Saudi Arabia. Further studies for investigating the incidence of brucellosis in ruminant animals all over the country are recommended. 


\section{ACKNOWLEDGMENT}

We thank Mr. Abdulaziz Al-Thebyani, Mr. Ahmad Al-Ghamdi, Mr. Ahmad Al-Malki, Mr. Ahmad Melibary, Mr. Bander Al-Harthi and Mr. Eyad Ebrahim for their assistant during sample collection and practical work. We also thank Mr. Omer Basheer for helping in the collection of blood samples from human beings.

\section{FUNDING}

This work was kindly supported by the Custodian of the Two Holly Mosques Institute of Hajj and Umrah Research and the Faculty of Applied Medical Science, Umm Al-Qura University, P.O. 6287, 21955 Makkah, Saudi Arabia.

\section{REFERENCES}

Afzal, M. and Sakkir, M. (1994): Survey of antibodies against various infectious disease agents in racing camels in Abu Dhabi, United Arab Emirates. Rev. sci. tech. Off. int. Epiz., 13, 787-792.

Al-Eissa, Y.A. (1999): Brucellosis in Saudi Arabia: Past, present and future. Annals of Saudi Medicine; 19, 403-405.

Al-Eissa, Y.A.; Kambal, A.M.; Al-Rabeeah, A.A.; Abdullah, A.M.; Al-Jurayyan, N.A. and AlJishi, N.M. (1990): Osteoarticular brucellosis in children. Ann Rheum Dis., 49, 896-900.

Alton, G.G. and Forsyth, J.R.L. (1996): Brucella, chapter 28. In: Medical Microbiology, $4^{\text {th }}$ ed.; Edited by Samuel Baron. University of Texas Medical Branch at Galveston, Galveston, Texas. http://www.ncbi.nlm.nih.gov/books/ NBK8572/

Bilal, N.E.; Jamjoom, G.A.; Bobo, R.A.; Aly, O.F.M. and El-Nashar, N.M. (1991): Brucellosis in the Asir region of Saudi Arabia. Saudi Med J., $12,37-41$.

Corbel, M.J. (1997): Brucellosis: an overview. Emerg Infect Dis., 3, 213-221.

Corbel, M.J. and MacMillan, A.P. (1999): Brucellosis, Chapter 41. Volume III. In: Topley and Wilson's, Microbiology and microbial infections, $9^{\text {th }}$ ed.; Hausler W.J., Sussman M., eds. Arnold, London.

Corbel, M.J. and Beeching N.J. (2004): Brucellosis, Chapter 141. Pp 914-917. In: Harrison's textbook of Internal Medicine, $16^{\text {th }}$ ed; McGraw-Hill, New York.

El-Ansary, E.H.; Mohammed, B.A.; Hamad, A.R. and Karom, A.G. (2001): Brucellosis among animals and human contacts in Eastern Sudan. Saudi Med. J., 22, 577-579.
Fallatah, S.M.; Oduloju, A.J.; Al-Dusari, S.N. and Fakunle, Y.M. (2005): Human brucellosis in Northern Saudi Arabia. Saudi Med J.; 26(10): 1562-1566.

Gul, S.T. and Khan, A. (2007): Epidemiology and epizootiology of brucellosis: A review. Pakistan Vet. J., 27, 145-151.

Kambal, A.M.; Maghoub, E.S.; Jamjoom, G.A. and Chowdhury, M.N.H. (1983): Brucellosis in Riyadh, Saudi Arabia: a microbiological and clinical study. Trans $R$ Soc Trop Med Hyg., 77, 820-824.

Kato, Y.; Masuda, G.; Itoda, I.; Imamura, A.; Ajisawa, A. and Negishi, M. (2007): Brucellosis in a returned traveler and his wife: probable person-to-person transmission of Brucella melitensis. J. Travel Med., 14, 343-345.

Kiel, F.W. and Khan, M.Y. (1987): Analysis of 506 consecutive positive tests for brucellosis in Saudi Arabia. $J$ Clin Microbiol, 25, 1384-1387.

Magwedere, K.; Bishi, A.; Tjipura-Zaire, G.; Eberle, G.Y.; Hemberger, Hoffman, L.C. and Dziva, $F$. (2011): Brucellae through the food chain: the role of sheep, goats and springbok (Antidorcus marsupialis) as sources of human infections in Namibia. J. S. Afr. Vet. Assoc., 82, 205-212.

Memish, Z. (2001): Brucellosis control in Saudi Arabia: prospects and challenges. $J$. Chemother., 13, 11-17.

Omer, M.K.; Skjerve, E.; Holstad, G.; Woldehiwet, Z. and MacMillan, A.P. (2000): Prevalence of antibodies to Brucella spp. in cattle, sheep, goats, horses and camels in the State of Eritrea; influence of husbandry systems. Epidemiol. Infection., 125, 447-453.

Pappas, G.; Papadimitriou, P.; Akritidis, N.; Christou, L. and Tsianos, E.V. (2006): The new global map of human brucellosis. Lancet Infect Dis., 6, 91-99.

Radwan, A.I.; Asmar, J.A.; Frerichs, W.M.; Bekairi, S.I. and Al-Mukayel, A.A. (1983): Incidence of brucellosis in domestic livestock in Saudi Arabia. Trop Anim Health Prod., 15, 139-143.

Refai, M. (2000): Control of brucellosis in animals in Egypt. In: Proc. $2^{\text {nd }}$ Intern. Symp. cumWorkshop of the Germany-Egypt-Region Inter-Alumni-Net (GEAR), St. Catherine, Germany.

Refai, M. (2002): Incidence and control of brucellosis in the Near East region. Vet Microbiol., 90, 81-110.

Seimenis, A.; Morelli, D. and Mantovani, A. (2006): Zoonoses in the Mediterranean region. Ann Ist Super Sanita., 42, 437-445. 
Sharma, V.D.; Sethi, M.S.; Yadav, M.P. and Dube, D.C. (1979): $\quad$ Sero-epidemiologic investigations on brucellosis in the states of Uttar Pradesh (U.P.) and Delhi (India). Int. J. Zoonoses, 6, 75-81.

Solera, J.; Martinez-Alfaro, E. and Espinosa, A. (1997): Recognition and optimum treatment of brucellosis. Drugs., 53, 245-256.

World Health Organization WHO (1998): WHO Expert Committee on Brucellosis. WHO, Geneva, 1-100.
World Health Organization WHO (2009): Bovine brucellosis in in Manual of Diagnostic Tests and Vaccine for Terrestrial Animals. Chapter 2.4.3. Available at: ww.oie.int/fileadmin /Home/eng/Health_standards/tahm/2.01.05_F MD.pdf.

Young, E.J. (1991): Serologic Diagnosis of Human Brucellosis: Analysis of 214 Cases by Agglutination Tests and Review of the Literature. Clin Infect Dis., 13 (3): 359-372.

\section{الإصابة بميكروب البروسيلا في الحيوانات المجترة والبثر الذين هم على اتصال وثيق بها في المنطقة الغربية بالمملكة العربية السعودية في عام 2012

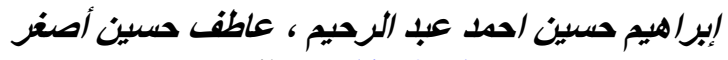 \\ Email: vetrahim@yahoo.com}

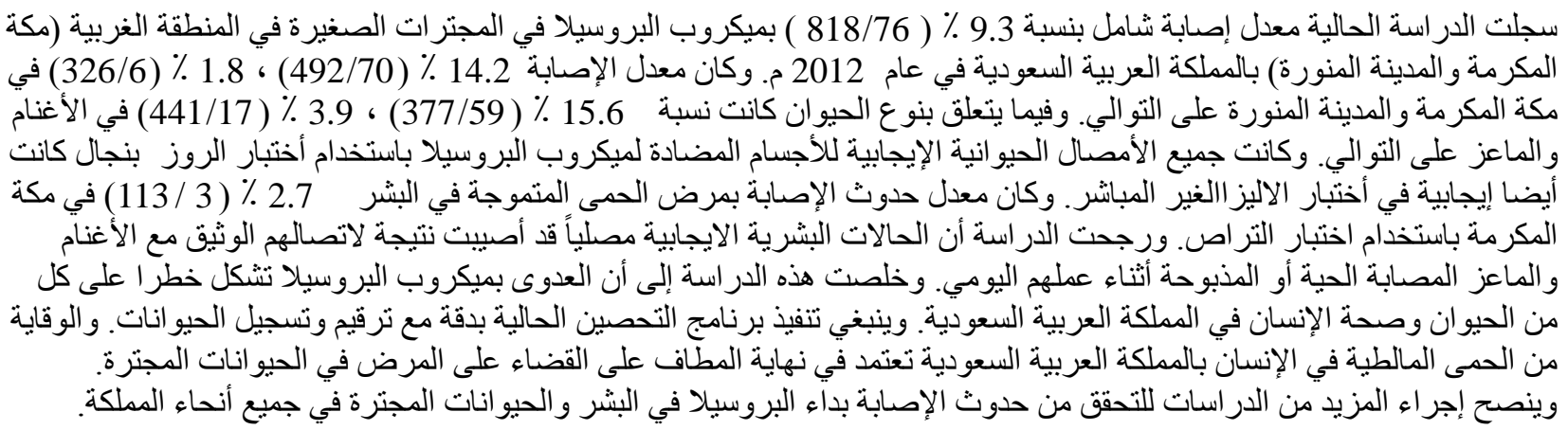

